\title{
Conus ependymoma with holocord syringomyelia
}

\author{
Sir, \\ Intramedullary spinal tumors are well known \\ to be associated with secondary syringomyelia. \\ Ependymomas and hemangioblastomas are the most \\ common tumors associated with syringomyelia. ${ }^{[1]}$ \\ However, holocord syringohydromyelia secondary to \\ intramedullary spinal tumors is extremely rare. ${ }^{[2,3]} \mathrm{We}$ \\ present one such rare case.
}

A 20-year-old male patient presented with complaints of progressive paraparesis and bladder and bowel incontinence of one year duration. On examination, he had flaccid paraparesis with motor power of $3 / 5$ in both the lower limbs. He also had dissociative sensory loss with pain and temperature being affected more than touch and vibration sensations. Contrast-enhanced magnetic resonance imaging (MRI) of the spine revealed a well-defined intramedullary mass at the level of D11-L1 vertebrae with inhomogenous postcontrast enhancement with associated holocord syrinx extending from C2-L2 vertebrae [Figure 1]. The patient underwent D11-L1 laminectomy and total microsurgical excision of the intramedullary lesion. Intraopeartively, the tumor was greyish-white, moderately vascular, and encapsulated with a good plane of cleavage between the tumor and the surrounding cord. Histopathological examination confirmed the diagnosis of ependymoma. He was doing well at the last follow-up six months after surgery and his sensorimotor symptoms had improved significantly. However, he was still incontinent and on urinary catheter. 


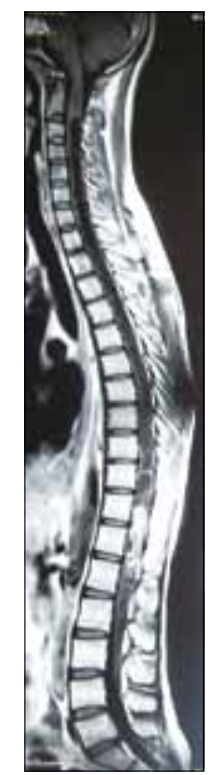

Figure 1: Gadolinium-enhanced magnetic resonance imaging of the spine showing a well-defined heterogenously contrast-enhancing mass at D11-L1 level with accompanying holocord syringohydromyelia

MRI spine done did not show any evidence of residual tumor and partial resolution of syrinx.

Spinal ependymomas are the most common intramedulary spinal cord tumor in adults and commonly involves conus medullaris ${ }^{[4]}$ Holocord syrinx is more commonly reported in association with Chiari I malformation ${ }^{[5]}$ and also in association with spinal hemangioblastomas. ${ }^{[2]}$ Spinal hemangioblastomas are highly vascular tumors and account for $1.6-2.1 \%$ of all primary spinal cord tumors. ${ }^{[6]} \mathrm{Up}$ to $50 \%$ cases of spinal hemangioblastomas are associated with syrinx formation. ${ }^{[7]}$ However, holocord syringohydromyelia in association with spinal cord tumors is extremely rare. The pathophysiology of syringohydromyelia associated with intramedullary spinal cord tumors appears to be most likely due to transudation of fluid from the pathological tumor vessels. The other possible mechanisms include obstruction to CSF flow in the central canal and extracellular perimedulary fluid flow. Regardless of histology, the higher the spinal level, the more likely the syrinx formation..$^{[1,2]}$

Gadolinium-enhanced MRI of spine is the investigation of choice for intramedullary tumors with syringomyelia. The presence of an associated syrinx suggests the resectability of the tumor, because it indicates a displacing rather than an infiltrating tumor. Patients with syringomyelia tend to recover from surgery earlier. No specific treatment of the syrinx is necessary and the syrinx usually resolves with excision of the tumor, as in our case. ${ }^{[1]}$
Sachin A. Borkar, G. D. Satyarthee, B. S. Sharma, Department of Neurosurgery, All India Institute of Medical Sciences, New Delhi, India. E-mail: duttaguru2002@yahoo.com

DOI: $10.4103 / 0028-3886.53271$

\section{References}

1. Samii M, Klekamp J. Surgical results of 100 intramedullary tumors in relation to accompanying syringomyelia._Neurosurgery 1994;35:865-73.

2. Pai SB, Krishna KN. Secondary holocord syringomyelia with spinal hemangioblastoma: A report of two cases. Neurol India 2003;51:67-8.

3. Sarikaya S, Acikgöz B, Tekkök IH, Güngen YY. Conus ependymoma with holocord syringohydromyelia and syringobulbia. J Clin Neurosei 2007;14:901-4.

4. Moser FG, Tuvia J, LaSall P, Llana J. Ependymoma of the spinal nerve root: Case report. Neurosurgery 1992;31:962-4.

5. Kumar J, Kumar A, Gupta S. Neurological pictures. Chiari I malformation with holocord syrinx. J Neurol Neurosurg Psychiatry 2007;78:146.

6. Isu T, Abe H, Iwasaki Y, Akino M, Koyanagi I, Hida K, et al. Diagnosis and surgical treatment of spinal hemangioblastomas. No Shinkei Geka 1991;19:149-55.

7. Rengachary SS, Blount JP. Hemangioblastomas In: Wilkins RH, Rengachary SS, editors. Neurosurgery. Vol. 1. Mc Graw Hill; 1996. p.1205-19.

Accepted on 25-03-2009 